\title{
ANÁLISE DE REQUISITOS PARA IMPLEMENTAÇÃO DE UMA FERRAMENTA DE AUTORIA PARA O DESENVOLVIMENTO DE OBJETOS DE APRENDIZAGEM PARA A ÁREA DA SAÚDE
}

\author{
Marta Rosecler Bez - Universidade Feevale - martabez@feevale.br \\ Angélica Luísa Nienow - Universidade Feevale - anienow@gmail.com \\ Cecília Dias Flores - UFCSPA - dflores@ufcspa.edu.br
}

\begin{abstract}
Resumo: Com a mudança das diretrizes para o ensino da medicina no Brasil, os objetos de aprendizagem se tornaram importantes ferramentas pedagógico-didáticas, pois trazem a possibilidade da construção de novos modelos organizativos do currículo. Para construir esses elementos podem ser usadas ferramentas de autoria. $O$ uso das ferramentas de autoria quase sempre exige conhecimentos avançados em informática, tornando-se um processo complicado para a grande maioria dos profissionais da saúde e do ensino. Neste artigo é proposta a análise para o desenvolvimento de uma ferramenta de autoria, tendo por base o estudo de ferramentas disponíveis atualmente, entrevista com professores da área da saúde e os principais padrões de metadados existentes.
\end{abstract}

Palavras chave: ferramentas de autoria; objetos de aprendizagem informática na educação; padrões de metadados.

\section{ANALYSIS OF REQUIREMENTS FOR IMPLEMENTATION OF AN AUTHORING TOOL FOR THE DEVELOPMENT OF LEARNING OBJECTS FOR THE HEALTH AREA}

\begin{abstract}
With the changing guidelines for the Brazil medicine teaching, learning objects use has become an important teaching tool, as they bring the possibility of building new organizational models of the curriculum. To build these elements can be used authoring tools. The use of authoring tools often requires advanced knowledge in computing, making it a complicated process for the vast majority of health professionals and education. This paper proposes an analysis for the development of an authoring tool, based on the study of tools currently available, interviews with teachers in the health area and the main metadata standards exist.
\end{abstract}

Keywords: authoring tool; learning objects; computing in education; metadata standards.

\section{Introdução}

Uma das etapas mais complexas para os educadores é a construção dos objetos de aprendizagem. Essa construção ocorre através de ferramentas de autoria, que também são conhecidas como ferramentas de autor, ferramentas aliadas, sistemas de criação de conteúdo, sistemas de autoria ou editores de objetos de aprendizagem.

Os editores de objetos de aprendizagem oferecem ambientes para a criação de conteúdos digitais padronizados. Seu objetivo principal é oferecer o maior número de recursos possíveis, em uma única ferramenta, para facilitar essa tarefa. Recursos como a conversão e junção de arquivos de áudio, vídeo e texto são exemplos de algumas capacidades disponíveis nesses aplicativos (VICARI et al., 2009). Assim como nos objetos de aprendizagem, existem diversas definições para ferramentas de autoria. 
Para o W3C (2009), ferramenta de autoria é qualquer aplicativo, parte de um aplicativo, ou coleção de aplicativos com as quais o autor interage para criar, modificar ou montar conteúdo web, que será utilizado por outras pessoas. Esta também é definida por Maia (2002) como "recursos amigáveis para que leigos ou não programadores, possam desenvolver com rapidez, amigabilidade e onde quer que estejam, independente de tempo, lugar ou situação física, um determinado conteúdo ou programa”.

Conforme Falkembach, Geller e Silveira (2006), as ferramentas de autoria oferecem um ambiente integrado para a combinação do conteúdo e das funções do software desenvolvido. Essas ferramentas fornecem a estrutura necessária para a organização e edição dos elementos de um software multimídia, incluindo gráficos, desenhos, animações, sons e vídeos. São utilizadas para o desenvolvimento da interface do software, visando estimular a interatividade, agrupando os elementos da multimídia num projeto coeso. As ferramentas de autoria mais elaboradas são os sistemas de autoria. Estes sistemas permitem, além de criar, editar e importar vários tipos de mídias, o desenvolvimento de código de programação, para responder a entradas do usuário.

Outra característica observada nas ferramentas de autoria pesquisadas é a geração de objetos em conformidade com padrões de metadados. Essa característica facilita o compartilhamento, descoberta e reutilização dos objetos de aprendizagem criados. Alguns desses editores apresentam recursos simples que atendem apenas uma ou outra característica citada anteriormente, outras auxiliam o projetista na criação, empacotamento e publicação do objeto de aprendizagem, oferecendo grande quantidade de recursos e a possibilidade de conformidade com diversos padrões existentes.

Com a comparação e classificação dos editores pesquisados e testados, foi possível identificar quais delas melhor atendem as necessidades de criação de objetos de aprendizagem na área da saúde e utilizá-las como base para a modelagem de dados. Dessa forma, os recursos já desenvolvidos poderão ser aproveitados e melhorados. Além disso, novas funcionalidades específicas para o desenvolvimento de objetos de aprendizagem na área da saúde poderão ser criadas.

\section{Análise de ferramentas de autoria}

Para o desenvolvimento deste projeto foram analisadas quatro ferramentas de autoria instaladas em um computador e testadas buscando conhecer características importantes que podem ser incorporadas na ferramenta a ser desenvolvida.

O Ardora (ARDORA; 2009) é uma ferramenta livre, que permite a criação de diversos tipos de atividades, como: quebra-cabeças, associações entre figuras e textos, exercícios com textos, sons e imagens, palavras cruzadas, etc. O conteúdo de todas as atividades pode ser textual e/ou gráfico, bem como podem incorporar diversos sons, imagens, animações ou vídeos. A interface é simples e permite a criação de atividades para todos os níveis de ensino, desde a educação infantil até o ensino superior. Atividades como colorir, quebra-cabeças, completar palavras com sílabas e letras podem ser utilizadas na criação de objetos de aprendizagem para as séries iniciais, bem como atividades mais complexas, com textos, vídeos, associação de imagens. Permite criar pacotes de atividades, com diversos OA (objeto de aprendizagem), que serão executados em uma sequência determinada pelo autor. Além disso, o software é compatível com o SCORM (Sharable Content Object Reference Model), o que permite a integração das atividades em ambientes como o Moodle.

O CourseLab (COURSELAB; 2009) é uma ferramenta de autoria gratuita, capaz de exportar os seus conteúdos para o SCORM. O editor sistematiza o conteúdo produzido em um formato similar à visualização de slides. Com essa ferramenta de 
autoria é possível criar um conjunto de módulos que podem ser utilizados com o Power Point ou disponibilizados em sistemas de aprendizagem. O software dispõe de vários recursos prontos e suporte à construção de animações. Além de múltiplas formas de criação de conteúdo, também pode ser utilizado para a criação de atividades e questionários, que enviam os resultados do desempenho do estudante para um SGC (Sistema Gerenciador de Cursos) através da interface SCORM. Um diferencial do CourseLab é a possibilidade de inserção de agentes em cada módulo ou OA criado. Esse agente tem opções que podem ser configuradas, de forma que ele tome ações prédeterminadas de acordo com a interação do estudante.

O eXe-Learning (EXE-LEARNING; 2009) é uma ferramenta de autoria de código aberto, que pode ser instalada em computadores ou executada diretamente de dispositivos USB. É executada em um navegador web e permite que o autor visualize os resultados durante a produção dos conteúdos. As produções são feitas diretamente sobre páginas HTML (HyperText Markup Language). O software pode exportar também o conteúdo produzido para a plataforma SCORM. Suporta filmes, animações, sons, arquivos em formato pdf, applets Java, feeds, vídeos do Youtube, Wikibooks, entre outros. Oferece suporte pedagógico através de iDevices. O "i" vem de instructional, dando à palavra o sentido de "ferramenta ou unidade instrucional". O eXe também dispõe de um editor WYSIWUG (What You See Is What You Get), que pode ser utilizado em todos os $i$-Devices. Esse editor facilita a formatação dos textos e permite a inclusão de elementos multimídia.

O Xerte (XERTE; 2009) é uma ferramenta de autoria gratuita e de código aberto, desenvolvida pela Universidade de Nottingham, no Reino Unido. Permite a criação de objetos de aprendizagem de duas maneiras: inserindo elementos e recursos disponíveis em menus ou através de edição de código fonte. Esta ferramenta disponibiliza vários recursos, que permitem a criação de conteúdos interativos em Flash. Permite inserir diferentes tipos de páginas, que ficam relacionadas em um menu a esquerda durante a execução do objeto de aprendizagem.

\subsection{Avaliação das ferramentas de autoria}

Após pesquisar sobre cada uma das ferramentas descritas e utilizá-las para a criação de recursos educacionais, foi elaborada uma tabela com o propósito de avaliar a facilidade de uso, a simplicidade da interface, a quantidade e a qualidade de cada uma das ferramentas.

Para a classificação, foi utilizada a seguinte escala de pontuação: Um: ruim, não atende ao mínimo exigido pelo usuário, é de difícil utilização, não existem mensagens de ajuda e de erro adequadas. Dois: regular, não apresenta todos os recursos necessários para a criação de bons objetos de aprendizagem, o uso dos recursos existentes é complicado, as mensagens de erro e de ajuda não são satisfatórias. Três: bom, apresenta vários recursos para a criação de objetos de aprendizagem, mas a sua utilização não atende totalmente as expectativas do usuário. Existem mensagens de erro e de ajuda em alguns momentos do processo de criação dos OA. Quatro: muito bom, apresenta diversos recursos, a sua utilização não é complicada, os recursos são de fácil localização na interface, existem mensagens de ajuda e erro em praticamente todos os níveis de construção dos objetos. Cinco: excelente, apresenta diversos recursos, a utilização é simples, é possível integrar diferentes elementos (textos, imagens, vídeos, sons), os recursos são de fácil localização na interface, existem mensagens de erro e de ajuda adequadas.

Tabela 1 - Avaliação das ferramentas de autoria

FATOR $\quad$ FERRAMENTAS DE AUTORIA




\begin{tabular}{l} 
CINTED-UFRGS \\
\cline { 2 - 5 } \\
\begin{tabular}{|l|c|c|c|c|}
\hline & Ardora & CourseLab & eXe-Learning & Xerte \\
\hline Facilidade de uso & 4 & 2 & 4 & 3 \\
\hline Simplicidade & 4 & 2 & 4 & 3 \\
\hline Quantidade de recursos disponíveis & 3 & 4 & 5 & 4 \\
\hline Qualidade dos recursos disponíveis & 3 & 4 & 5 & 3 \\
\hline
\end{tabular}
\end{tabular}

Dentre as ferramentas avaliadas, o Ardora e o eXe-Learning se destacaram, pois apresentam diversos recursos para trabalhar com textos e multimídia. Outras duas características apresentadas nestas, consideradas fundamentais, são a simplicidade e a facilidade de uso.

Entre os vários tipos de criação de atividades disponibilizados pelo Ardora, se destacam as categorias de relacionar e classificar. Ambas disponibilizam recursos para criar objetos de aprendizagem com imagens e textos. É possível criar objetos onde o estudante deverá relacionar imagens com outras imagens ou com textos, ou ainda onde será necessário classificar imagens em categorias.

Dentre os i-Devices disponíveis na ferramenta eXe, para o uso na área da saúde e que podem ser implementados na ferramenta a ser modelada, destacam-se os seguintes: Estudo de caso, Questões de múltipla escolha, Reflexão como método de conectar teoria a prática, Artigos Wiki e Feeds RSS.

\section{Análise para o desenvolvimento de uma ferramenta de autoria}

A etapa de levantamento de requisitos busca compreender as necessidades dos usuários e quais funções o sistema a ser desenvolvido deve desempenhar. Os dados para elencar os requisitos são obtidos, na sua maioria, através de entrevistas aos usuários e testes de sistemas. Conforme Medeiros (2004), nessa etapa, é preciso obter todos os requisitos necessários para a construção dos casos de uso, pois todo o resto da modelagem estará baseado na documentação dos mesmos.

Optou-se por modelar uma ferramenta que permita construir objetos de aprendizagem em formato semelhante ao de uma página web. Esse formato é ideal para a utilização dos OA em ambientes virtuais de aprendizagem, além de poder ser executado em um browser, facilitando o acesso a partir de qualquer dispositivo. Um mesmo objeto poderá conter diversas atividades, que serão acessadas via browser e realizadas na sequência desejada pelo aluno. O professor poderá criar atividades, inserir vídeos, imagens, jogos, apresentações de slides e textos. As atividades e outros elementos estarão dispostos em um menu lateral, facilitando a navegação.

Com base nos resultados de um questionário aplicado aos professores da área da saúde de duas universidades, foi possível descobrir quais as funcionalidades das ferramentas de autoria já existentes que são mais utilizadas pelos mesmos. Estas estão descritas a seguir, juntamente com algumas funcionalidades presentes nas ferramentas de autoria pesquisadas e consideradas importantes para a criação de objetos de aprendizagem.

\subsection{Diagrama de Caso de Uso}

O diagrama de caso de uso é o mais geral e informal da UML (Unified Modeling Language) e costuma ser utilizado nas fases de levantamento de requisitos e análise do sistema, além de servir de base para todos os demais diagramas da modelagem de dados (GUEDES, 2008).

O diagrama de caso de uso apresentado na Figura 1 demonstra as funcionalidades da ferramenta de autoria. $\mathrm{O}$ ator representa dois usuários que irão interagir de forma 


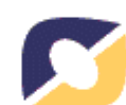

simultânea. Um deles é o usuário externo que utilizará a ferramenta para criar OA e o outro é o sistema, ambos interagindo com todos os casos de uso.

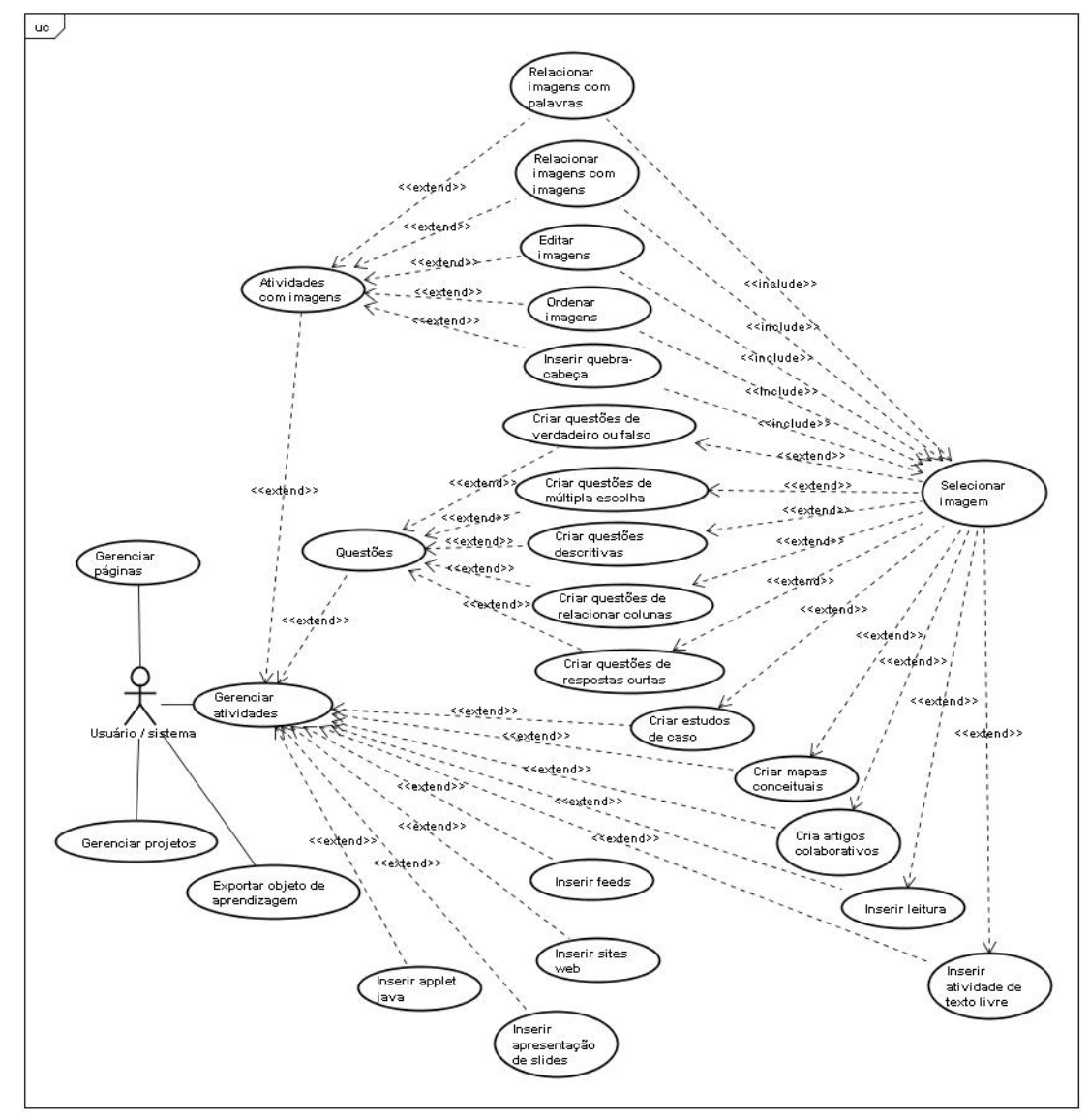

Figura 1 - Diagrama de Caso de Uso

\subsection{Requisitos}

"Requisito é uma condição ou capacidade que um software deve ter" (MEDEIROS; 2004; p. 43). Para Blaha e Rumbaugh (2006), os requisitos descrevem como um sistema deve se comportar partindo do ponto de vista dos usuários. Os autores Dennis e Wixom (2005) seguem a mesma linha, afirmando que um requisito é uma declaração do que o sistema deve ser ou quais as características ele deve ter. A seguir são descritos os requisitos funcionais (REQF) da ferramenta de autoria proposta.

REQF01 - Inserir página: corresponde à inserção de novas páginas no OA. Todo objeto deve ter ao menos uma página, onde poderão ser criadas uma ou mais atividades. O usuário poderá definir um plano de fundo e um título para a página. Estas ficarão dispostas em um quadro, na lateral esquerda da tela da ferramenta.

REQF02 - Modificar página: corresponde à modificação de páginas no OA. As páginas criadas ficarão dispostas em um quadro, na lateral esquerda da tela. Para modificá-las, o usuário deve clicar sobre o nome da página e fazer as edições desejadas.

REQF03 - Excluir página: corresponde à exclusão de uma ou mais páginas do OA. Toda página poderá ser excluída, sendo excluídas as atividades que constarem na mesma. Para a exclusão, o usuário deverá utilizar o quadro de páginas do REQF01.

REQF04 - Inserir atividade: corresponde à criação de uma nova atividade. O usuário poderá acessar as possibilidades de atividades através do menu "Inserir”. Para 
que uma atividade possa ser inserida é necessária ao menos uma página. O título da atividade criada aparecerá abaixo do título da sua página, no quadro citado no REQF01.

REQF05 - Modificar atividade: corresponde à modificação de atividades criadas em algum momento anterior. Para acessar uma atividade, o usuário deverá utilizar o quadro de páginas citado no REQF01.

REQF06 - Excluir atividade: corresponde à exclusão de uma ou mais atividades criadas. Para a exclusão, deverá utilizar o quadro citado no REQF01.

REQF07 - Salvar projeto: corresponde à opção de salvar um projeto criado com a ferramenta de autoria. O projeto conterá todas as páginas e atividades inseridas e poderá ser editado posteriormente. Ao selecionar a opção "Salvar" ou "Salvar como", do menu “Arquivo", será aberta uma janela, na qual o usuário selecionará o local onde o projeto será salvo e o nome do mesmo. Essa deve ter um botão de procurar o local, uma caixa de texto para nomear o arquivo, um botão para salvar e outro para cancelar.

REQF08 - Abrir Projeto: corresponde à opção de abrir um projeto criado anteriormente. Ao selecionar a opção “Abrir”, do menu “Arquivo”, será aberta uma janela, na qual o usuário selecionará o local onde o projeto se encontra e o projeto a ser aberto. Essa janela deve ter um botão de procurar, para selecionar o local, uma caixa de texto para nomear o arquivo, um botão para abrir e outro para cancelar.

REQF09 - Novo Projeto: corresponde à opção de criar um novo projeto. Ao selecionar a opção "Novo”, do menu “Arquivo", será criado um novo projeto. Se houver algum projeto aberto, o sistema solicitará que o mesmo seja salvo e fechado.

REQF10 - Fechar Projeto: corresponde à opção de fechar um projeto. Essa ação estará disponível de três maneiras: o botão "Fechar", localizado no canto superior direito da interface, na opção "Fechar" ou "Fechar Projeto", do menu "Arquivo". As duas primeiras formas também encerram a execução da ferramenta. A terceira fecha o projeto, mas mantém a ferramenta aberta, para que possam ser abertos ou criados novos projetos. Se o projeto não estiver salvo, o sistema solicitará que o mesmo seja feito.

REQF11 - Exportar objeto de aprendizagem: corresponde à opção de exportar um projeto criado anteriormente em formato HTML, SCORM e outros a serem analisados no desenvolvimento da ferramenta. Essa opção estará disponível no menu "Arquivo", "Exportar”, onde será aberta uma janela, em que o usuário selecionará o local de destino e o nome do arquivo. Essa janela deve ter um botão para selecionar o local, caixa de texto para nomear o arquivo, botão para exportar e outro para cancelar.

REQF12 - Relacionar imagens com palavras: corresponde à criação da atividade de relacionar imagens com textos. Nessa atividade deverão constar: campo de texto para título, campo de texto para descrição da atividade, botão para inserir imagens, campo de texto para digitar uma palavra relacionada com a imagem, campo de texto para digitar uma mensagem parabenizando o aluno e outra para uma mensagem que o estimule a tentar novamente, além de um botão de confirmação e um de cancelamento.

REQF13 - Relacionar imagens com imagens: corresponde à criação da atividade de relacionar imagens com outras imagens. Nessa atividade deverão constar: campo de texto para título, campo de texto para descrição da atividade, botão para inserir as imagens principais e outro para inserir as imagens relacionadas, listbox para selecionar o código de associação das imagens, campo de texto para digitar uma mensagem parabenizando o aluno e outra para digitar uma mensagem que o estimule a tentar novamente, além de um botão de confirmação e um de cancelamento. 


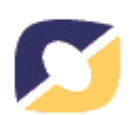

REQF14 - Editar imagens: corresponde à criação da atividade que permitirá elencar uma série de tarefas que deverão ser executadas com a edição de uma ou mais imagens. Nessa atividade deverão constar: campo de texto para título, campo de texto para descrição da atividade, botão para inserir imagem, campos de texto para elencar todas as tarefas que deverão ser realizadas durante a execução do objeto de aprendizagem, botão para inserir mais tarefas, campo de texto para digitar uma mensagem parabenizando o aluno e outra para digitar uma mensagem que o estimule a tentar novamente, além de um botão de confirmação e um de cancelamento.

REQF15 - Ordenar imagens: corresponde à criação da atividade de ordenar imagens em uma sequência definida pelo professor. Nessa atividade deverão constar: campo de texto para título, campo de texto para descrição da atividade, botão para inserir imagens, campo para informar a sequência da imagem, campo de texto para digitar uma mensagem parabenizando o aluno e outra para digitar uma mensagem que 0 estimule a tentar novamente, além de um botão de confirmação e um de cancelamento.

REQF16 - Inserir quebra-cabeça: corresponde à criação da atividade de quebra-cabeça. Nessa atividade deverão constar: campo de texto para título e para descrição da atividade, botão para inserir imagens, campo para informar a quantidade de peças, um campo para informar o tempo em minutos que o aluno terá, campo de texto para digitar uma mensagem parabenizando o aluno e outra para digitar uma mensagem que o estimule a continuar, além de um botão de confirmação e um de cancelamento.

REQF17 - Selecionar Imagem: corresponde à inserção de imagens nas atividades. As atividades que utilizarem imagens conterão um botão "Selecionar Imagem”. Quando clicar nesse botão, o sistema abrirá uma nova janela contendo um campo para o endereço da imagem, um botão para buscar imagens, dois campos para definir altura e largura da imagem, um checkbox de proporções, uma área para vista prévia da imagem, um botão de confirmação e um de cancelamento.

REQF18 - Questões de verdadeiro ou falso: corresponde à criação de questões de verdadeiro ou falso. Deverão constar: um campo de texto para título, um botão para inserir imagens, um botão para inserir nova sentença, um campo de texto para digitar a sentença, radio button para informar se a resposta é verdadeira ou falsa, um botão para excluir e um para modificar uma sentença criada, campo de texto para digitar uma mensagem parabenizando o aluno e outra para digitar uma mensagem que o estimule continuar, além de um botão para confirmação e outro para cancelamento.

REQF19 - Questões de múltipla escolha: corresponde à criação de questões de múltipla escolha. Deverão constar: um campo de texto para título, um botão para inserir imagens, um botão para inserir nova questão, um botão para inserir nova resposta, checkbox para marcar a respostas correta, um botão para excluir e um para modificar a questão, um botão para excluir e um para modificar uma resposta, campo de texto para digitar uma mensagem parabenizando o aluno e outra para digitar uma mensagem que $o$ estimule a continuar, além de um botão para confirmação e outro para cancelamento.

REQF20 - Questões descritivas: corresponde à criação de questões descritivas. Deverão constar: um campo de texto para título, um campo de texto para digitar a questão, um botão para inserir imagens, um botão para inserir nova questão, campo para definir o tamanho do campo de texto que aparecerá para o aluno digitar a resposta durante a execução do OA, um botão para excluir e um para modificar uma questão criada, além de um botão para confirmação e outro para cancelamento. 


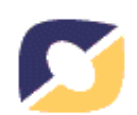

REQF21 - Relacionar colunas: corresponde à criação de questões de relacionar colunas. Deverão constar: um campo de texto para título, um campo de texto para a descrição da atividade, um botão para inserir imagens, um botão para inserir nova relação, campos de texto para digitar a sentença da primeira e segunda colunas, um botão para excluir e outro para modificar relacionamentos criados, campo de texto para digitar uma mensagem parabenizando o aluno e outra para digitar uma mensagem que $o$ estimule a continuar, um botão para embaralhar as alternativas da segunda coluna, um para confirmação e outro para cancelamento.

REQF22 - Questões de respostas curtas: corresponde à criação de questões com respostas curtas. Deverão constar: um campo de texto para título, um campo de texto para uma frase, um botão para inserir imagens, um botão para inserir nova frase, campo de texto para informar a palavra que será removida, botão para inserir mais palavras, botão para excluir e um para modificar uma frase criada, campo de texto para digitar uma mensagem parabenizando o aluno e outra para digitar uma mensagem que o estimule a continuar, além de um botão para confirmação e outro para cancelamento.

REQF23 - Mapas conceituas: corresponde à criação de atividades onde o professor irá inserir um texto, que será utilizado pelo aluno durante a execução do OA para criar um mapa conceitual. Deverão constar: campo de texto para o título, um botão para inserir novo texto para mapa, um para modificar e outro para excluir textos inseridos, além de um botão para confirmação e outro para cancelamento. Quando o ator clicar no botão "Novo Mapa”, será exibida uma tela com área de texto para inserir um texto, do qual, durante a execução do OA, o aluno deverá retirar as palavras para criar o mapa conceitual. Nessa tela também haverá um botão para inserir imagens, um botão para confirmar e outro para cancelar a criação do texto para o mapa conceitual.

REQF24 - Estudos de caso: corresponde à criação de atividades com estudos de caso. Nessa atividade deverão constar: campo de texto para título, um botão para inserir um novo estudo de caso, um botão para modificar e outro para excluir casos de uso inseridos, além de um botão de confirmação e um de cancelamento. Ao clicar no botão "Inserir Estudo de Caso", será aberta uma nova tela com uma área de texto para descrever o problema a ser resolvido pelo aluno, um botão para inserir imagens, uma área de texto para descrever a solução, campo para definir o tamanho do campo de texto que aparecerá para o aluno digitar a resposta durante a execução do objeto de aprendizagem, um botão para confirmação e outro para cancelamento do estudo de caso.

REQF25 - Artigos colaborativos: corresponde à inserção de artigos colaborativos no objeto de aprendizagem. Deverão constar: um campo de texto para título, um campo de texto para descrição, um botão para inserir artigo, um botão para excluir e um para modificar cada artigo inserido. Quando o ator clicar no botão "Inserir Artigo", o sistema apresentará uma tela onde haverá um campo para inserir o texto inicial do artigo, dois campos para definir altura e largura da área de edição, um checkbox para manter ou não proporções dessa área, três radio buttons para definir o alinhamento (centralizado, direito, esquerdo), além de um botão para confirmação e outro para cancelamento. Durante a execução do OA, o aluno terá uma interface com opções de edição do artigo, de forma a alterar o texto inicial ou complementá-lo, tanto com frases como com imagens. Cada artigo poderá ser editado por todos os alunos que estiverem executando o OA no mesmo ambiente de aprendizagem.

REQF26 - Feeds: corresponde à inserção de feeds de determinados sites no OA. Deverão constar: um campo de texto para título, um campo de texto para descrição, um botão para inserir feed, um botão para excluir e um para modificar cada feed 
inserido, campo de texto para informar o link do qual devem ser buscados os feeds, uma área de texto para exibir os feeds carregados a partir do endereço informado, um campo para informar a quantidade de notícias a ser exibido na execução do OA, além de um botão para confirmação e outro para cancelamento.

REQF27 - Sites da web: corresponde à inserção de sites no OA. Deverão constar: um campo de texto para título, um campo de texto para descrição, um botão para inserir site, um botão para excluir e um para modificar cada site inserido, campo de texto para informar o link do site, além de um botão para confirmação e outro para cancelamento. Durante a execução do objeto de aprendizagem, quando um aluno clicar sobre o link de um site, o mesmo deverá ser aberto em outra aba ou janela do browser, de forma a não interromper a realização das atividades do OA.

REQF28 - Apresentação de slides: corresponde à inserção de apresentação de slides nos OA. Deverão constar: um campo de texto para título, um campo de texto para descrição, um botão para inserir apresentação, um botão para excluir e um para modificar a apresentação inserida, além de um botão para confirmação e outro para cancelamento. Quando o ator clicar no botão "Inserir Apresentação”, o sistema abrirá uma nova janela, onde aparecerá um campo para o endereço da apresentação, um botão para buscar apresentações, dois campos para definir altura e largura da área onde a apresentação será exibida no objeto de aprendizagem, um checkbox para manter ou não proporções dessa área, três radio buttons para definir se a apresentação será exibida no centro, lateral direita ou lateral esquerda da tela, uma área onde aparecerá uma vista prévia da apresentação, um botão de confirmação e um de cancelamento.

REQF29 - Applet Java: corresponde à inserção de applets Java nos OA. Deverão constar: um campo de texto para título, um campo de texto para descrição, um botão para inserir applet, um botão para excluir e um para modificar cada applet inserido, além de um botão para confirmação e outro para cancelamento. Quando o ator clicar no botão "Inserir Applet”, o sistema abrirá uma nova janela, onde aparecerá um campo para o endereço do applet, um botão para buscar applets, dois campos para definir altura e largura da área onde o applet será exibido, um checkbox para manter ou não proporções dessa área, três radio buttons para definir se o applet será exibido no centro, lateral direita ou lateral esquerda da tela, uma área onde aparecerá uma vista prévia do applet, um botão de confirmação e um de cancelamento.

REQF30 - Leitura: corresponde à inserção de leituras no objeto de aprendizagem. Deverão constar uma área de texto para inserir a leitura (digitar ou colar - se o texto for colado e tiver formatações prévias ou imagens, o sistema deverá manter as mesmas), um botão para confirmação e outro para cancelamento.

REQF31 - Atividade de texto livre: corresponde à inserção de atividades de texto livre, onde o professor definirá um tema sobre o qual o aluno deve dissertar. Deverão constar: um campo de texto para título, uma área de texto para o tema, um botão para inserir imagens, um campo de texto para informar a quantidade de caracteres usáveis, além de um botão para confirmação e outro para cancelamento.

REQF32 - Formatar atividades: corresponde à formatação das atividades que serão criadas pelo ator. Todos os campos de texto poderão ser formatados utilizando as ferramentas da barra de formatação. Entre os recursos estão: cor, tamanho e tipo da fonte, alinhamento dos textos, marcadores e numeração, recuos, espaçamento entre linhas, bordas, negrito, itálico, sublinhado, copiar, recortar e colar. Além disso, poderá ser formatada a cor de fundo da atividade, utilizando o botão "Preenchimento". 


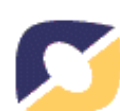

REQF33 - Calcular percentual de acerto: corresponde a uma verificação que será feita durante a resolução das atividades pelos alunos. Sempre que uma atividade for concluída, o sistema deverá verificar o percentual de acertos.

\section{Conclusão}

Este trabalho apresenta o levantamento de requisitos para o desenvolvimento de uma ferramenta de autoria para material educacional e objetos de aprendizagem para a área da saúde, tendo como aspecto o princípio da facilidade de uso.

O estudo bibliográfico realizado mostrou que a tecnologia está cada vez mais presente nos diferentes contextos educacionais. Dessa forma surge a necessidade de interação entre alunos, professores e tecnologia, com o objetivo de melhorar o processo de ensino e aprendizagem.

O que pode ser observado, na maioria das ferramentas de autoria analisadas, foi a complexidade de utilização das mesmas. A maioria dos professores não apresenta esse conhecimento avançado e, muitas vezes, precisa de ajuda de experts em informática para utilizá-las. Buscando sanar este problema, é proposto o desenvolvimento de uma ferramenta de autoria, que permita a qualquer professor, com pouco conhecimento em informática, desenvolver e disponibilizar OA on-line. Os próximos passos são a descrição dos casos de uso estendidos e a montagem dos protótipos de intefaces, para, posteriormente, iniciar o desenvolvimento.

Um dos aspectos importantes deste projeto é a participação dos futuros usuários no desenvolvimento da ferramenta, professores da área da saúde, fornecendo sugestões, material didático para análise, críticas, e prontificando-se para testes com a ferramenta.

\section{Referências Bibliográficas}

ARDORA. Disponível em: <www. webardora.net>. Acesso em 20/08/2009.

BLAHA, M.; RUMBAUGH, J.. Modelagem e projetos baseados em objetos com UML 2. Rio de Janeiro: Campus, 2006.

COURSE LAB. Disponível em: <www.courselab.com>. Acesso em 23/08/2009.

DENNIS, A.; WIXOM, B. H.. Análise e projeto de sistemas. RJ: LTC, 2005.

EXE LEARNING. Disponível em: <www.exelearning.org>. Acesso em 26/08/2009.

FALKEMBACH, G. A. M.; GELLER, M.; SILVEIRA, S. R.. Desenvolvimento de Jogos Educativos Digitais utilizando a Ferramenta de Autoria Multimídia: um estudo de caso com o ToolBook Instructor. CINTED - UFRGS, 2006. Disponível em: $<$ www.cinted.ufrgs.br/renote/jul2006/artigosrenote/a12_21147.pdf $>$. Acesso em: 22/06/2009.

GUEDES, G. T. A. UML: uma abordagem prática. 3. ed. SP: Novatec Editora, 2008. MAIA, C.. Ferramentas aliadas. Revista Aprender. Edição Set./Out. 2002. Disponível em: <www.universia.com.br/materia/materia.jsp?id=970>. Acesso em: 24/08/2009.

MEDEIROS, E. S.. Desenvolvendo Software com UML 2.0: definitivo. SP: Pearson Makron Books, 2004.

VICARI, R. et al. Padrão para Metadados de Objetos de Aprendizagem Multiplataforma. Porto Alegre: UFRGS, 2009.

XERTE. Disponível em: <www.nottingham.ac.uk/xerte/xerte.htm>. Acesso em: 30/08/2009.

W3C. Authoring Tool Accessibility Guidelines 2.0 - Working Draft. Disponível em: <www.w3.org/TR/ATAG20>. Acesso em: 10/11/2009. 